\title{
Spherical connective tissue inclusions in epithelial hyperplasia of the breast ("collagenous spherulosis")
}

\author{
C A Wells, C W Wells, P Yeomans, M Viña, S Jordan, A J d'Ardenne
}

\begin{abstract}
Partial myoepithelial differentiation is common in simple epithelial hyperplasia (epitheliosis) of the breast but functional myoepithelial differentiation with basement membrane production is exceedingly rare. A peculiar change of hyaline globules within benign epithelial hyperplasia has been recognised before as "collagenous spherulosis" and type IV collagen has been shown by immunohistochemistry. Another seven cases are described which show the presence of laminin and collagens IV and III within the proliferation. Electron microscopical examination of two cases using material retrieved from the wax block showed varying degrees of myoepithelial differentiation of the cells immediately surrounding the spherules and basal lamina material, including mature collagen fibrils in one case. The degree of myoepithelial differentiation of the cells surrounding the spherules seemed to correlate with the differing types and amounts of extracellular matrix in the spherule.
\end{abstract}

Histopathologists should be aware of this rare change as it may be misinterpreted as in situ carcinoma.

In 1987 Clement, Young, and Azzopardi described a peculiar change within the lumina of breast acini and ductules which they designated "collagenous spherulosis". This change had been noted in referral material where it had occasionally been confused with malignancy, especially adenoid cystic carcinoma, and in archival material. The authors of this paper were able to show that the hyaline material within the intraluminal space was rich in collagen by conventional histochemistry, and in a subsequent letter they were able to show one component of basement membrane by immunocytochemistry. ${ }^{2}$ We present a further seven cases with immunohistochemical results showing the varying proportions of basal lamina proteins and interstitial collagens in the spherules. In two cases this was confirmed by ultrastructural examination of tissue taken from the paraffin wax blocks.

\section{Methods}

Cases of "collagenous spherulosis" were identified in tissue sections from the files of the John Radcliffe Hospital by reviewing 934 biopsy specimens diagnosed as fibrocystic change or one of its synonyms. One case referred for opinion to CAW was also included (courtesy of Dr W Harrison, North Middlesex Hospital).

Blocks were recut, and where sufficient material was available, sections were stained by the immunoperoxidase technique, with appropriate controls, for laminin (Gibco Ltd), type IV collagen (Euro-diagnostics Ltd), type I and type III collagen (Bio-Nuclear Services Ltd), S-100 protein (Dako Ltd), and actin (Amersham Diagnostics Ltd).

Laminin, collagen, types I, III, and IV immunostaining were performed using the avidin-biotin complex method with 25 minutes in pronase type 24 (Sigma Ltd) for digestion. Actin immunostaining was performed by the avidin-biotin complex method using 10 minutes of trypsin digestion. S100 immunostaining was performed by the peroxidaseantiperoxidase method using 10 minutes of trypsin digestion.

In two cases the abnormal area could be identified from the paraffin wax block and a portion of the lesion was retrieved for electron microscopical examination. This area was excised from the block, dewaxed in xylene, and rehydrated through graded alcohol into $0 \cdot 1 \mathrm{M}$ cacodylate buffer ( $\mathrm{pH} 7 \cdot 4$ ). This was then fixed in $3 \%$ gluteraldehyde, post-fixed in $1 \%$ osmium tetroxide, dehydrated and embedded in TAAB premix resin. Semi-thin $(0.5 \mu \mathrm{m})$ sections were cut and stained with toluidine blue. Ultrathin sections $(70 \mathrm{~nm})$ were cut, stained with uranyl acetate and lead citrate, and viewed in a JEOL 100 SX transmission electron microscope.

Case follow up was performed as described previously. ${ }^{3}$

\section{Results}

"Collagenous spherulosis" was found in six of the 934 biopsy specimens reviewed, an incidence of $0.64 \%$, and a further referred case was studied. The age range of patients from whom biopsy specimens had been taken was 26 to 47 years (mean 40.4 years). Follow up was available on four, one of whom was registered as having breast carcinoma with the Oxford Cancer Registry in 1974, having had a benign biopsy showing "collagenous spherulosis", moderate simple hyperplasia (epitheliosis), papillary apocrine metaplasia, and a radial scar in 1965. The carcinoma was of poorly differentiated ductal type with lymph node metastases. Three other patients are alive with no evidence 


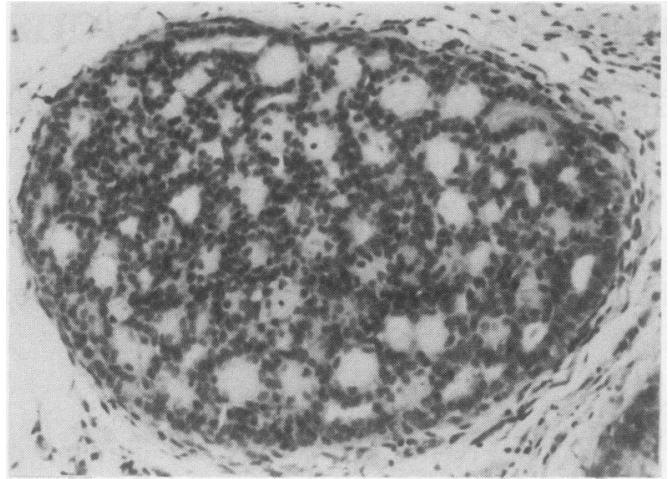

Figure 1 "Collagenous spherulosis" showing amorphous rounded hyaline material in an intraluminal location within a ductule. Note the occasional epithelial lumina (haematoxylin and eosin).

of breast carcinoma 30, 27, and 23 years after their benign breast biopsy. No follow-up information is available for the other two patients.

\section{HISTOPATHOLOGY}

"Collagenous spherulosis" was present as an incidental finding in all cases apart from the referral case where it was associated with a radial scar and was an integral part of the abnormality. The appearances on haematoxylin and eosin staining were as described previously, ${ }^{1}$ and showed discrete hyaline or fibrillar material within a sieve-like intraacinar or intraductular proliferation (fig 1), accompanied by a dimorphic population of cells. The cells immediately surrounding the spherules showed some spindling reminiscent of myoepithelial differentiation while cells with pure epithelial appearances, surrounding lumina often containing secretion, were located away from the spherules. The change was intimately associated with a radial scar in three of the seven cases, with an area of nodular sclerosing adenosis in one, and in three cases was found incidently in small ductules or acinar units not associated with another lesion. Fibrocystic changes were noted elsewhere in the tissue in all cases.

\section{IMMUNOHISTOCHEMISTRY}

Laminin staining showed a characteristic appearance in all the lesions in which further

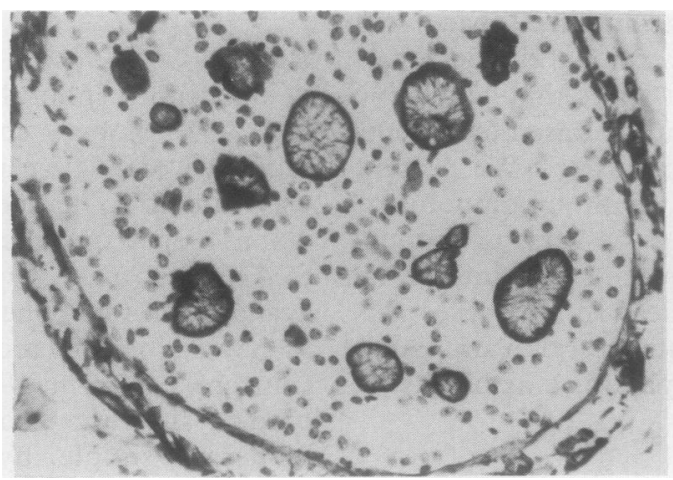

Figure 2 Laminin immunoreactivity showing characteristic circumferential positivity and "spider-like" processes extending to a central core (laminin immunoperoxidase).

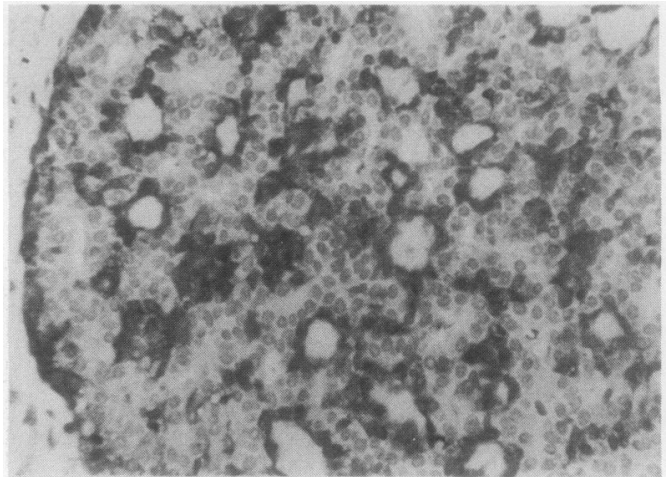

Figure 3 S100 immunoreactivity showing positive cells surrounding the amorphous hyaline material and negative cells surrounding true epithelial lumina ( S100 immunoperoxidase).

sections were available for study (all but one case). This was present in a linear form around the edge of the spherules similar to that seen in adenoid cystic carcinoma. ${ }^{45}$ In five of the six cases there was also a spider-like distribution within the spherules themselves (fig 2). Type IV collagen staining was performed on cases where material was still available and the staining pattern was similar to the laminin distribution, and as described previously. ${ }^{2}$ S100 staining showed that the cells immediately surrounding the spherules were uniformly positive with negative cells surrounding occasional epithelial lumina (fig 3). Actin staining was only possible on the referral case due to technical problems, but it showed faint staining of the same cells as in the $S 100$ immunostain. Immunostaining for types I and III collagen showed that occasional spherules contained small amounts of immunoreactivity. This was most conspicuous in the case with absent basal lamina proteins in the centre of the spherules.

\section{ELECTRON MICROSCOPY}

Preservation of the tissue was remarkably good considering that the tissue had been embedded in paraffin wax for some 30 years, although fixation was suboptimal.

At low magnification the lesion appeared as a number of spheres surrounded by proliferated cells (fig 4). The proliferation was all contained

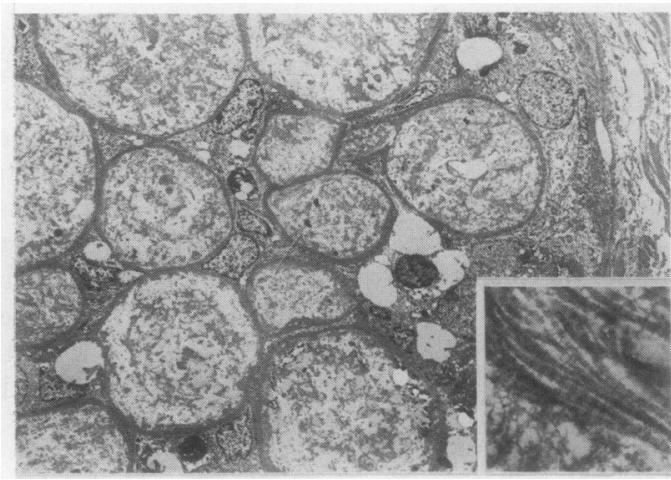

Figure 4 Low power electron micrograph showing the spherules within a ductule.

Insert: high power view of collagen fibres from the core of a spherule showing characteristic striations. 


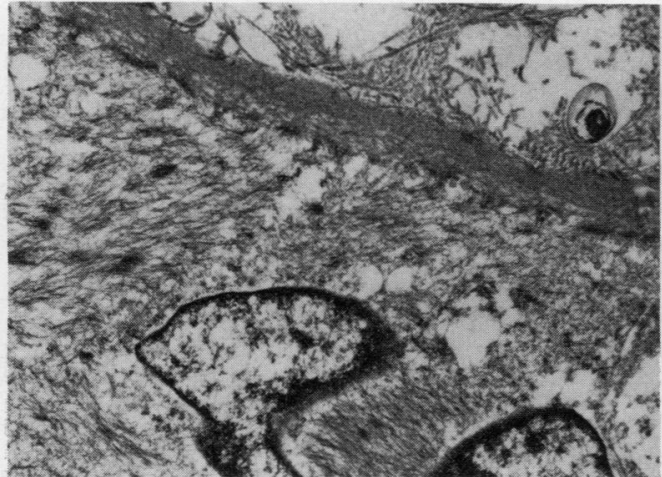

Figure 5 Myoepithelial cell showing cytoplasmic filaments, dense bodies, and hemidesmosomes attaching the cell to the basement membrane surrounding the collagen core of a spherule.

within ductules or acinar spaces.

In the first case studied, at higher magnification, the spherules were shown to consist of a mature collagen core (fig 4 , insert) surrounded by an intact basement membrane layer (fig 5).

Subtending the basement membrane were cells showing the full spectrum of myoepithelial differentiation, with hemidesmosomes attached to the basement membrane and parallel arrays of microfilaments with dense bodies (fig 5). One or two true epithelial lumina with microvilli and surrounded by epithelial cells joined by desmosomes and tight junctions (fig 6 and insert) were identified within the proliferation.

In the second case the core of the spherule was completely devoid of mature collagen fibres and seemed to contain a central basement membrane core and radiating strands of reduplicated basement membrane extending from the centre to the peripheral rim. Between the strands the matrix was electron-lucent (fig 7). The cells subtending the spherules showed hemidesmosomes, again attached to the basement membrane material, but microfilaments and dense bodies were not generally seen.

These appearances mirrored the immunohistological findings, the first case studied being the case with no radiating strands on the laminin immunostaining and with strong positive immunoreactivity for collagens I and III. The second case was more typical of the group as a whole.

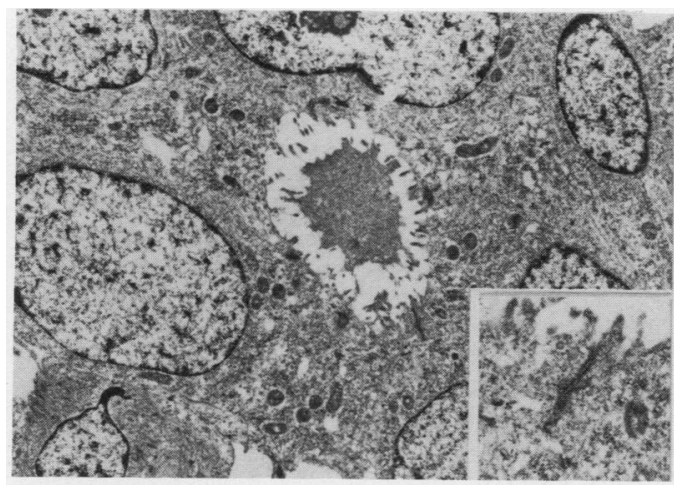

Figure 6 Epithelial lumen with microvilli and mucin secretion in an area of "collagenous spherulosis". Insert tight junction at high power from the epithelial cells seen in the main figure.

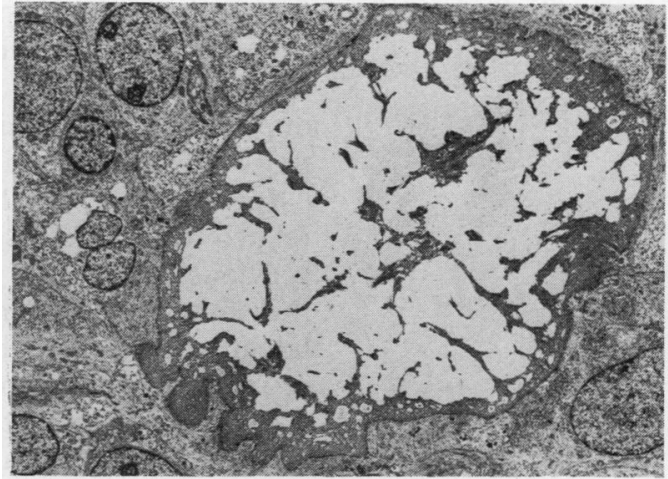

Figure 7 Spherule from the second case studied demonstrating the lack of a collagen core and radiating basement membrane strands.

\section{Discussion}

The finding of laminin and type IV collagen in the spherules within "collagenous spherulosis" suggests that the spherules contain basement membrane material, which confirms the findings of the previous study. ${ }^{12}$ This would suggest that the lesion is an extreme example of myoepithelial differentiation in epithelial hyperplasia of the breast. Additional support for this can be seen in the results with $S 100$ and actin staining. ${ }^{1}$ Although $\mathrm{S} 100$ protein does not mark myoepithelial cells exclusively ${ }^{36}$ as was originally thought, ${ }^{7}$ the combination of weak actin staining with this suggests myoepithelial differentiation. $^{6}$ The electron microscopic appearances also strongly support this.

"Collagenous spherulosis" seems to be a little heterogeneous in that some cases show a mature collagen core to the spherules while in most cases the spherules contain reduplicated basal lamina only, without mature collagen. This suggests that in some examples there is a more "mature" type of spherule with a collagenous centre surrounded by basement membrane. The electron microscopical results sugggest that the degree of collagen formation within the spherule is related to the degree of myoepithelial differentiation of the cells surrounding the spherule, and suggests that this change occurs due to production of basement membrane material and, in some cases, mature collagen by the myoepithelial component of the proliferation.

Myoepithelial cell production of interstitial collagen fibres is often seen in benign salivary tumours such as plemorphic adenomata. There were no vessels or fibroblasts within any of the spherules, indicating that these were not papillary cores.

The lesion bears a similarity to adenoid cystic carcinoma ${ }^{45}$ in its light and electron microscopic appearances and the immunocytochemical staining. Both lesions contain two types of lumina, one surrounded by cells showing epithelial differentiation and containing epithelial mucin, the other surrounded by cells showing myoepithelial differentiation and containing basement membrane material. Interstitial collagen fibres, while numerous in the spherules of the first example of "collagenous spherulosis" at electron microscopy, are rarely 
found in the pseudocysts of adenoid cystic carcinoma, ${ }^{5}$ but the electron microscopic appearances of the second case with reduplicated basal lamina were very similar to those of adenoid cystic carcinoma.

Interestingly, the lesion often seems to be related to radial scars, and this was true of the previous study and our own. Its detection, therefore, may well increase in frequency as a larger number of radial scars are removed as a result of breast screening programmes.

In common with the previous authors ${ }^{1}$ we emphasise the benign nature of this lesion and alert practising histopathologists to the entity so as to avoid the misdiagnosis of this lesion as either adenoid cystic carcinoma or cribriform carcinoma of either in situ ${ }^{8}$ or invasive types. ${ }^{9}$ This may be a special problem when the lesion is associated with a radial scar which may show pseudo-infiltration. The recognition of the low power appearance of intra-acinar proliferation around a hyaline core with pseudo-infiltration is crucial to the diagnosis. This contrasts with the haphazard arrangement of in situ carcinoma and infiltrating tubules within the basophilic desmoplastic stroma of a tubular carcinoma.

Basal lamina immunohistology can be helpful in these cases, provided it is interpreted with care. ${ }^{9}$
We thank $\mathrm{Dr}$ W Harrison and $\mathrm{Mr} J \mathrm{M}$ Beaugie for kind permission to report one of their cases; $D r$ W Gullick for the kind permission to report one of their cases; Dr W Gullick for the kind provision of antibodies; Mr J Hopwood for photographic
assistance; Dr R Holloway, Dr B Don, Mrs Jane Orr and Mrs assistance; Dr R Holloway, Dr B Don, Mrs Jane Orr and Mrs Practitioners in Oxfordshire who helped with follow up inforPractitioners in Oxfordshire who hel
mation on women in their practices.

This work was partially supported by a research grant from Oxford Regional Health Authority (No 88/17).

AJd'A is supported, in part, by the Imperial Cancer Research Fund.

1 Clement PB, Young RH, Azzopardi JG. Collagenous spherulosis of the breast. Am J Surg Pathol 1987;11 411-17.

2 Clement PB. Collagenous spherulosis. Am J Surg Pathol 1987;11:907.

3 Viña M, Wells CA. Clear cell metaplasia of the breast: a lesion showing eccrine differentiation. Histopathol 1989;15:85-92.

4 d'Ardenne AJ, Kirkpatrick P, Wells CA, Davis JD. Laminin and fibronectin in adenoid cystic carcinomas. $J$ Clin Pathol 1986;39:138-44.

5 Wells CA, Nicol SM, Ferguson DJP. Adenoid cystic carcinoma of the breast-a case with proven lymph node metastasis. Histopathol 1986;10:415-24.

6 Gillett CE, Bobrow LG, Millis RR. S100 protein in human mammary tissue-Immunoreactivity in breast carcinoma including Paget's disease of the nipple, and value as a marker of myoepithelial cells. J Pathol 1990;160:19-24.

7 Egan MJ, Newman J, Crocker J, Collard M. Immunohistochemical localisation of $\mathrm{S} 100$ protein in benign and malignant conditions of the breast. Arch Pathol Lab Med malignant condition

8 Page DL, Anderson TJ, Rogers LW. Cribriform and micropapillary carcinoma in-situ. In: Diagnostic histopathology of the breast. London: Churchill Livingstone, 1987:163-74.

9 Page DL, Anderson TJ, Sukamoto G. Invasive cribriform arcinoma. In: Diagnostic histopathology of the breast. London: Churchill Livingstone, 1987:227-35.

10 d'Ardenne AJ. Use of basement membrane markers in tumour diagnosis. J Clin Pathol 1989;42:449-57. 